\title{
AVALIAÇÃO DO COMPORTAMENTO HIDROLÓGICO NA BACIA DO RIBEIRÃO ENTRE RIBEIROS, AFLUENTE DO RIO PARACATU, EM CENÁRIO DE MUDANÇA CLIMÁTICA COM O USO DO SOFTWARE STELLA
}

\author{
Maurício Novaes Souza ${ }^{1}$, Everardo Chartuni Mantovani², Aziz Galvão da Silva Júnior ${ }^{3}$, James Jackson Griffith \\ Rafael Coll Delgado
}

\begin{abstract}
RESUMO
A ocorrência de fenômenos meteorológicos e climatológicos extremos se tornou fato. Apesar da adoção de medidas emergenciais, alguns problemas se intensificaram: incremento da concentração de gases de efeito estufa; diminuição da camada de ozônio; redução das terras agricultáveis; crescente contaminação dos ecossistemas aquáticos e redução progressiva dos recursos de água doce. Um dos fatores agravantes dessa situação se refere à substituição da vegetação nativa, realidade da bacia do ribeirão Entre Ribeiros, afluente do rio Paracatu, onde a atividade "Irrigação" apresenta forte incremento. Nessa bacia tem ocorrido a substituição de "Cerrado" (-47,65\%) por "Cultivo" (+198,09\%), que diminui a interceptação da água da chuva, aumenta o escoamento superficial e reduz a infiltração de água no solo, causando redução das vazões médias e mínimas. Nesse estudo, por meio da modelagem baseada em princípios de "Dinâmica de Sistemas" e com o uso do software STELLA, simulou-se possíveis efeitos das mudanças climáticas na referida bacia, considerandose acréscimos de $1{ }^{\circ} \mathrm{C}$ na temperatura e de $6,9 \%$ na precipitação no período $1995-2060$. Verificou-se a tendência de uma redução de $-15,16 \%$ na "Precipitação direta" e significativas alterações nas taxas evapotranspirométricas para "Pasto" (+33,34\%); "Cultivo" (+23,77\%); "Cerrado" (+8,54\%); e "Mata" (-9,49\%).
\end{abstract}

Palavras-chave: Mudanças climáticas, comportamento hidrológico, modelagem.

\section{ABSTRACT \\ EVALUATION OF HYDROLOGIC BEHAVIOR OF THE ENTRE RIBEIROS RIVER BASIN, AN AFFLUENT OF PARACATU RIVER, IN CLIMATIC CHANGE SCENARIO, WITH THE USE OF THE STELLA SOFTWARE}

Occurrence of extreme changes in the meteorological and climatologic phenomenon has become a fact. Despite adoption of emergency measures, some problems have intensified e.g. increase in the concentration of gases of heating effect; decrease of ozone layer; decline of agricultural land, increasing contamination of aquatic ecosystems and progressive decline of the resources of potable water. One of the aggravating factors for this situation is substitution of the native vegetation, a reality in the Entre Ribeiros river basin, increasing irrigation is replacing "Cerrado" (-47.65\%), by cultivation $(+198.9 \%)$. This has reduced rain water infiltration into the soil, thus reducing the average and the minimum flow. This study, simulated the possible effect of climate change, considering $1{ }^{\circ} \mathrm{C}$ increase of temperature and $6.9 \%$ of the precipitation during the period 1995-2060, through modeling based on the origin of "Dynamic of the Systems" with the use of the software STELLA. The results showed a tendency of decrease of $18.70 \%$ in the "Direct Precipitation" and significant alterations in the evapotranspirometric rate in pasture grass $(+33.34 \%)$, Cultivation $(+23.77 \%)$, "Cerrado" $(+8.54 \%)$ and Forest $(-9.49 \%)$.

Keywords: climatic changes, hydrologic behavior, modeling.

\section{Recebido para publicação em 19/11/2008. Aprovado em 17/12/2009}

1- Eng. Agrônomo, DSc., Prof. Titular IF SEMG campus São João Del Rei. E-mail: mauricios.novaes@ifsudeste.org.br.

2- Eng. Agrícola, Ph. D., Prof. Titular, DEA-UFV, Viçosa/MG. E-mail: everardo@ufv.br

3- Eng. Agrônomo, Ph. D., Prof. Adjunto, DER-UFV, Viçosa/MG. E-mail: aziz@ufv.br

4- Filósofo, Ph. D., Prof. Titular, DEF-UFV, Viçosa/MG. E-mail: griffith@ufv.br

5- Meteorologista, Doutorando DEA-UFV, Viçosa/MG. E-mail: rcdelgado@hotmail.com 


\section{INTRODUÇ̃̃O}

É indiscutível que alterações climáticas promovidas por fatores naturais tiveram e têm influência sobre a biosfera. Porém, a intervenção antrópica, principalmente com o desenvolvimento tecnológico acelerado das últimas décadas, tem quebrado essa dinâmica natural das formações originais, suprimindo-as e criando em seus lugares paisagens altamente modificadas, numa forma não sincronizada na relação homem/ambiente. Tais alterações têm sido danosas ao meio ambiente, por não se observarem os limites do crescimento, reduzindo a resistência e a resiliência dos ecossistemas (ODUM, 1988; RESENDE et al., 1996; SOUZA, 2004).

Diante dessa realidade, durante a Primeira Conferência Mundial sobre o Clima, em 1979, as mudanças climáticas foram reconhecidas como um sério problema a ser enfrentado pela comunidade internacional. A preocupação com a questão persistiu ao longo da década de 1980, quando foram realizadas várias conferências intergovernamentais para debatê-la. A Resolução 43/53 da Assembléia Geral das Nações Unidas criou, em 1988, o Painel Intergovernamental sobre Alterações Climáticas (IPCC), sob os auspícios da Organização Meteorológica Mundial (OMM) e do Programa das Nações Unidas para o Meio Ambiente (PNUMA) (SALATI, 1994).

Contudo, o acelerado crescimento econômico das últimas décadas tem levado à necessidade de grandes incrementos da produção industrial e agropecuária, os quais vêm sendo obtidos por meio da aplicação intensiva de novas tecnologias e pela abertura de novas fronteiras agropecuárias. Como conseqüência, alguns problemas vêm se intensificando, ou novos têm surgido. Os climatologistas do "Goddard Institute for Space Studies" (GISS) da NASA, descobriram que os anos de 1998 e 2007, foram os mais quentes do último século na Terra. Em uma análise da influência de nuvens e aerossóis em suspensão na atmosfera, demonstraram como a superfície terrestre tem refletido mais radiação do que absorvido: conseqüência de ações como a derrubada de florestas para a formação de pastagens ou cultivos. Desde a década de 1990, os sinais da mudança têm se mostrado de forma mais evidente, que de acordo com essa equipe de pesquisadores, deixa claro que o efeito estufa já promove mudanças climáticas no planeta (GISS, 2008).

Como consequência, vários cientistas, em todo o mundo, concordam que as mudanças climáticas já afetam, e afetarão ainda mais, o ciclo hidrológico; mas os impactos e a capacidade de remediação destes, quando possível, ocorrerão de formas diversas nas diferentes regiões (GLEICK \& KIPARSKY, 2004). Considerando a grande extensão do rio São Francisco e a diversidade de ambientes que compõem a sua bacia hidrográfica, a sua grande população, a geração de hidroeletricidade, a irrigação e a diluição de esgoto, que figuram entre os maiores usos dos recursos hídricos da bacia, tais efeitos poderão ser imprevisíveis e, ou, dramáticos (CBHSF, 2004).

Uma elevação da freqüência e da área de ocorrência das secas afetará o acesso e a distribuição da água da bacia hidrográfica. A redução dos recursos hídricos pode levar à ocorrência de desertos (OYAMA \& NOBRE, 2004); causar a escassez de água para consumo humano, para espécies de animais e plantas; destruir ou reduzir a produção e a produtividade agrícola; aumentar a demanda de água para irrigação; incrementar a migração populacional para centros urbanos (AB' SABER, 1999), entre outros. Considerando que $73,5 \%$ da vazão natural média do rio São Francisco é proveniente do estado de Minas Gerais (MMA \& SRH-MMA, 2006), dessa forma, a vazão do rio São Francisco seria seriamente afetada.

Da área de drenagem da bacia do rio Paracatu, afluente do rio São Francisco, cerca de 92\% encontram-se no Estado de Minas Gerais, 5\% em Goiás e 3\% no Distrito Federal (FERREIRA \& EUCLYDES, 1997). Um estudo realizado por PRUSKI et al. (2005), sobre a disponibilidade hídrica no rio São Francisco, evidenciou que, dentre as suas sub-bacias, a do Paracatu é a que apresenta a maior contribuição real (volume médio escoado), representando $19,5 \%$ do volume na foz do rio São Francisco.

Os grandes projetos de irrigação, que ocupam uma área de 37.150ha, constituem a principal fonte de conflitos, de natureza quantitativa, associados ao uso de água na bacia do rio Paracatu. O consumo de água nessa bacia aumentou cerca de onze (11) vezes no período 1970-1996, com uma taxa de crescimento do consumo de água de $0,20 \mathrm{~m}^{3} \mathrm{~s}^{-1} \mathrm{ano}^{-1}$, sendo $0,19 \mathrm{~m}^{3} \mathrm{~s}^{-1}$ ano $^{-1}$ correspondente ao aumento do consumo pela irrigação. Entre os seus principais afluentes, pode-se citar pela sua pela margem esquerda, o ribeirão Entre Ribeiros, objeto desse estudo, com uma área de drenagem de $3.973 \mathrm{~km}^{2}$ (ANA, 2003). 
Em 42\% (13.600ha) da bacia do rio Paracatu já ocorrem limitações quanto ao uso da água, principalmente na bacia do ribeirão Entre Ribeiros (RODRIGUEZ et al., 2007). Nesse local, tem ocorrido a intensificação de atividades agropecuárias e silviculturais, que substituem a vegetação nativa de "Cerrado". As vazões médias observadas em estações fluviométricas na bacia do ribeirão Entre Ribeiros são da ordem de $15,92 \mathrm{~m}^{3} \mathrm{~s}^{-1}$ e a vazão específica de $10,01 \mathrm{~L} \mathrm{~s}^{-1} \mathrm{~km}^{2}$, na estação fluviométrica Fazenda Barra da Égua (LATUF, 2007).

Além da consideração do grande aumento no consumo de água, a análise do efeito das mudanças climáticas também deve ter especial atenção por parte dos órgãos responsáveis pela gestão dos recursos hídricos. De acordo com as previsões climáticas por meio de modelos de circulação atmosférica para a bacia do rio São Francisco, Azevedo et al. (2005) constataram que nos próximos quarenta (40) anos a região onde se situa a bacia do Paracatu deverá sofrer, em média, aumentos de $6,9 \%$ da precipitação e de $1^{\circ} \mathrm{C}$ na temperatura média do ar. A quantificação do efeito decorrente de tais mudanças climáticas poderá permitir a definição de estratégias para garantir a disponibilidade hídrica necessária para que não venha ocorrer conflitos entre os usuários de água na bacia.

Considerando que a modelagem é uma ferramenta utilizada para melhor entender e representar o comportamento de uma bacia hidrográfica, a utilização dos modelos hidrológicos apresentará grande potencial para caracterizar a disponibilidade hídrica em condições de mudanças no clima ou no uso do solo.

Entretanto, um grande complicador para estudos relacionados às modificações do uso do solo em bacias hidrográficas, é que a maioria dos modelos hidrológicos não possui condições de simular tais modificações em uma bacia hidrográfica (TUCCI et al., 2001). Esta dificuldade está relacionada justamente ao fato de alguns parâmetros hidrológicos não serem estacionários, ou seja, a variabilidade temporal e espacial de seu comportamento é justificada, entre outros, pelas diferentes formas de uso do solo, que certamente acarretarão alterações na superfície da bacia, tendo impactos sobre seu comportamento hidrológico.

Deste modo, o conhecimento do comportamento espacial e temporal das variáveis hidrológicas é de suma importância para subsidiar a tomada de decisão na gestão de recursos hídricos, uma vez que permite quantificar a disponibilidade dos recursos hídricos no tempo e no espaço, ou seja, identificar áreas em que este recurso se encontra ou pode vir a se tornar escasso (RODRIGUEZ, 2004).

A análise do comportamento hidrológico decorrente de mudanças nas condições de usos do solo ou modificações destes é de grande importância para a gestão de recursos hídricos, sobretudo para a determinação de disponibilidades hídricas atuais e futuras. Há de se considerar como ponto relevante neste estudo, a importância da irrigação na produção de alimentos e na gestão da água, posto estar diretamente ligada com a questão da sustentabilidade ambiental.

\section{MATERIAL E MÉTODO}

A intensificação de atividades agrícolas e silviculturais, que substituem a vegetação nativa de "Cerrado" (-47,65\%) por "Cultivos" (+198,09\%), como também a intensificação da agricultura irrigada, é uma realidade na bacia hidrográfica do ribeirão Entre Ribeiros (LATUF, 2007). Dessa forma, as externalidades sócio-econômicas e ambientais na bacia em estudo estão associadas às intervenções antrópicas, que pela falta de técnicas de manejo no uso do solo, contribui significativamente para a degradação dos corpos de água e, conseqüentemente, para a redução de sua quantidade (SANTOS et al., 2007).

Nesse trabalho, os parâmetros necessários para a construção do modelo que representará a estrutura de oferta e demanda de recursos hídricos na bacia do ribeirão Entre Ribeiros, são de natureza secundária. Foram selecionados a partir das informações provenientes dos bancos de dados do (a): Agência Nacional das Águas (ANA); Instituto Brasileiro de Geografia e Estatística (IBGE); Instituto Nacional de Pesquisas Espaciais (INPE); Agência Nacional de Energia Elétrica (ANEEL); Plano Diretor de Recursos Hídricos da bacia do rio Paracatu (PLANPAR/Ruralminas); Companhia de Saneamento de Minas Gerais (COPASA); Departamento Nacional de Meteorologia do Brasil (DNM); e, principalmente, do estudo realizado por Latuf (2007).

O estudo desse último autor teve como um dos principais objetivos realizar o monitoramento do uso do solo da bacia do ribeirão Entre Ribeiros no período 1985-2000 e associar o comportamento hidrológico com as variações ocorridas pela 
mudança das classes de uso do solo. Para isso, contou com a análise da série temporal de oito (8) estações fluviométricas e onze (11) estações pluviométricas, no período 1985-2000, a fim de se obter a vazão máxima, média, mínimas $\left(\mathrm{Q}_{7}\right.$, $\mathrm{Q}_{90}$ e $\mathrm{Q}_{95}$ ) e específicas para cada ano do período selecionado, assim como, a precipitação média para cada área de drenagem das estações fluviométricas. Pôde-se concluir no trabalho desse mesmo autor, entre outros, a significativa substituição da cobertura vegetal do Bioma "Cerrado" e a redução das vazões na referida área de estudo.

Com relação à quantidade, considerando o complexo quadro de conflitos pelo uso da água evidenciado na bacia do ribeirão Entre Ribeiros, indica a necessidade de elaborar procedimentos confiáveis para a estimativa das disponibilidades hídricas e um modelo eficiente para a sua gestão. No entanto, a construção de um modelo implica em uma ampla investigação, além de um trabalho eminentemente criativo, que neste estudo foi estruturado por meio das seguintes etapas (ORELLANA GONZÁLEZ, 2006): a) conceitualização; b) formalização; e c) simulação esta etapa inclui a avaliação e exploração. As etapas de conceitualização e de formalização serão agora apresentadas; e a etapa de simulação, nos resultados e discussão.

\section{Etapa de conceitualização}

Existe um consenso de que projetar cenários só é possível com o entendimento do espaço natural e suas condições passadas e atuais: essa questão é complexa, dada às inter-relações existentes nos diversos ecossistemas - ao entender o que acontece nesse espaço é possível projetar cenários futuros e quantificar suas conseqüências. Desta forma, para ORELLANAGONZÁLEZ (2006), estaetapa consiste na familiarização dos problemas relacionados à área em estudo, tendo como objetivo defini-los. Assim, nesse estudo se buscou identificar os elementos que configuram o sistema de recursos hídricos da bacia, foram determinadas as principais variáveis e suas respectivas inter-relações, conformando-se assim, a estrutura do modelo de oferta e demanda hídrica.

Foi escolhido como horizonte de planejamento um período de sessenta e cinco (65) anos, que se enquadra acima do tempo mínimo de 25-30 anos, que é normalmente empregado para a implantação da maioria dos planos de desenvolvimento sócio- econômico (ibidem). Foi examinado o cenário "Mudança Climática", em comparação com o cenário "Agronegócio atual", que compreende futuros aumentos de demanda de água e na precipitação, além do aumento da temperatura, e restrições da oferta deste recurso, a fim de se avaliar a sustentabilidade do sistema.

Para o desenho do diagrama causal, que representa as relações principais e relevantes para o estudo da estrutura de oferta e demanda hídrica da bacia do presente estudo, se tomou como base o fluxograma (Figura 1) que contém os componentes principais da estrutura do modelo de recursos hídricos que analisa o balanço entre oferta e demanda de água (XU et al., 2002; ORELLANA GONZÁLEZ, 2006).

Conforma-se pelos agregados principais: o primeiro representa a oferta de água disponível; e o segundo que engloba a demanda do referido recurso. Destes grandes agregados se derivam o balanço hídrico do modelo - foi desenhado para representar a estrutura da demanda de água da produção agrícola e da demanda ambiental requerida para manter a vida dos ecossistemas da região. Compreende também a oferta de recursos hídricos disponíveis regionalmente, a qual foi estimada com base na vazão média $\left(\mathrm{Q}_{\text {med }}\right)$ do ribeirão Entre Ribeiros.

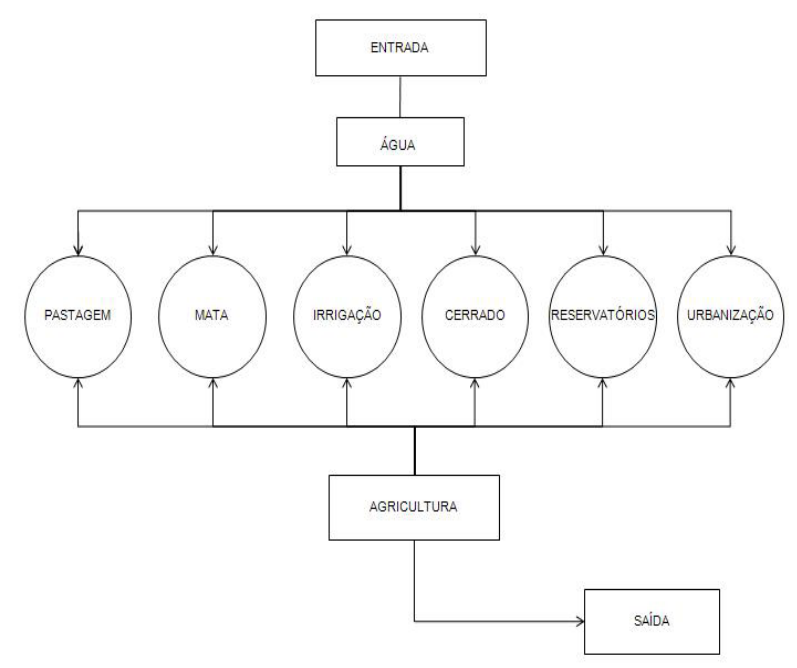

Figura 1. Fluxograma da estrutura do modelo da bacia do ribeirão Entre Ribeiros.

A elaboração e o entendimento desse fluxograma (Figura 1) permitiram estabelecer os principais componentes do modelo da bacia hidrográfica do ribeirão Entre Ribeiros, e identificar as relações de causalidade mais importantes que existem entre eles. Como resultado destas análises, se elaborou o diagrama causal específico (Figura 2). 


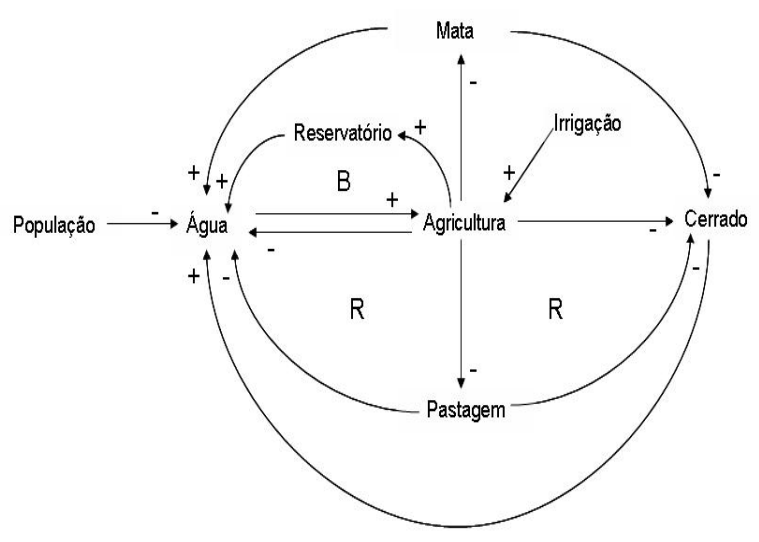

Figura 2. Diagrama causal do modelo da bacia hidrográfica do ribeirão Entre Ribeiros.

Na Figura 2 estão identificados os componentes básicos do sistema, bem como a interação que se dá entre eles, sendo esta última a que proporciona as características estruturais do sistema que nos ocupa. Apresenta-se "Água”, como a oferta de água disponível; "População", que indica a demanda de água para consumo doméstico; "Cerrado", que é o Bioma regional, representa produção e estoque de água; "Mata", incluem-se as florestas de galerias ou as ripárias, representam produção e estoque de água; "Agricultura" ou "Cultivo", engloba seus requerimentos hídricos e dos plantios florestais; e "Pastagem", evidenciando a demanda de água requerida por este setor.
A variável "Reservatórios" significa estoque de água (Balanceamento), em face da retenção do excesso de água que se perderia por escoamento superficial; e "Irrigação" considerada a variável que está dinamizando e incrementando as atividades do setor produtivo e de serviços, o fator de injeção de recursos financeiros nas atividades agrícolas, além de ser a maior responsável pela demanda de água da bacia.

Com respeito aos laços de realimentação existentes entre os componentes do sistema, destacam-se os seguintes pontos: a injeção de recursos financeiros provenientes da irrigação gera um impacto positivo sobre as atividades do setor agrícola, e se manifesta os efeitos de uma variável sobre outra que caminham na mesma direção, sendo representadas com um sinal $(+)$ ao final da seta (Figura 2). Por exemplo, se a atividade de irrigação aumenta, ela repercute em um aumento das atividades agrícolas, e viceversa.

Ao contrário, um aumento do consumo de água do setor agrícola, pecuário e da população, gera um impacto negativo sobre a oferta de água disponível; assegura que o crescimento destas variáveis ocasiona diminuição da oferta de água limpa, aumento da contaminação (não considerado nesse estudo), e vice-versa. Pode-se então afirmar que os efeitos caminham em direções contrárias, representadas com um sinal (-).



Figura 3. Diagrama de estoque e fluxo da bacia hidrográfica do ribeirão Entre Ribeiros 
Produto dos efeitos das relações entre as variáveis, o modelo está caracterizado, em síntese, por um laço de realimentação positivo (R). Significa que a variação de um elemento se propaga em toda a sua extensão reforçando a variação inicial, gerando um crescimento exponencial do sistema a partir de onde toda a variação é amplificada, provocando mais movimento na mesma direção. No caso da sustentabilidade dos recursos hídricos nessa bacia em estudo, torna-se um ciclo vicioso, que provoca uma piora do sistema quando se exerce pressão sobre a oferta do recurso água. Por outro lado, medidas que estimulem o estoque de água, que representa uma condição de aumento da sua oferta, cria uma situação de balanceamento do sistema (B), como é o caso dos "Reservatórios".

\section{Etapa de formalização}

Nesta etapa se efetuou a formalização do diagrama causal do modelo (Figura 2) empregando para isto uma linguagem matemática. O ponto de partida foi a elaboração do diagrama de estoque e fluxo, que de forma mais detalhada descreve o funcionamento do sistema (Figura 3), a partir do qual se escreveu as equações do modelo, tendo por base os dados da estação fluviométrica Fazenda Barra da Égua.

A conversão se deu da seguinte forma: uma vez representados no diagrama causal, os componentes principais do modelo de oferta e demanda de recursos hídricos das bacias (água, pastagem, mata, irrigação, cerrado, reservatórios, urbanização/população e agricultura/cultivo), assim como suas relações principais, que de forma abstrata é a base do enfoque do pensamento sistêmico; construiu-se e procedeuse a sua formalização em linguagem de Dinâmica de Sistemas, auxiliados pelas ferramentas empregadas na construção de modelos que se elaboram a base deste enfoque. As estruturas básicas para o desenho do diagrama são os estoques e os fluxos (Figura 2).

Os estoques representam no modelo as acumulações de recursos e também as restrições destes. Representam as condições, informando como está a situação; e suas variáveis que acumulam trocas influenciadas pelos fluxos. Neste caso, os estoques constituem por um lado, a água limpa que se denominou "água" e representa a oferta hídrica do modelo; e por outro, nesse trabalho, será considerado, principalmente, as áreas de "Cultivo", que determina a demanda de água requerida na bacia.

Os fluxos se representam com válvulas - identificam as ações que acumulam e, ou, esvaziam os estoques, e dizem como os fatos estão se desenrolando - são variáveis dependentes do tempo. Como se pode observar no modelo da Figura 3, temse os fluxos nomeados com taxas que são controladas pela (s) taxa (s) da (s) variável (is) em conexão, que usualmente é uma variável auxiliar ou uma constante, e que estão alimentando a oferta hídrica. Esta oferta está constituída pelas águas superficiais (ribeirão Entre Ribeiros) e seus respectivos escoamentos.

Por outra parte se têm os fluxos que representam a demanda hídrica do modelo. Estes estão compostos pelos requerimentos de água dos setores agrícola, pecuário, população urbana e rural, e pela demanda ambiental, constituída esta última, pela vazão mínima que o rio deve ter para manter a vida de seus ecossistemas correspondentes. Neste estudo, foi considerada a vazão mínima. Estas demandas têm um fluxo de saída que alimenta o estoque de água residual.

Os outros elementos do modelo evidenciados no diagrama causal, e que determinam os fluxos, se convertem em variáveis auxiliares ou constantes, tal como o consumo de água do setor agrícola, pecuário, populacional, entre outros. As relações entre as variáveis, que no diagrama causal se estabelecem por intermédio de flechas, neste diagrama se indicam da mesma forma, sendo chamados de conectores. Estes vinculam os estoques e as variáveis auxiliares ou as constantes; os estoques aos reguladores de fluxos; e as auxiliares ou as constantes a outras auxiliares ou constantes.

\section{Descrição matemática do modelo}

Os modelos de dinâmica de sistemas são construídos por meio de um conjunto de equações diferenciais, que são matematicamente resultantes ao longo de um período por um algoritmo que gera comportamentos dependentes do tempo para as variáveis contidas no modelo. Parte das equações está embutida no programa e não estão aqui relacionadas (equações "time", expressas como equação diferencial). A seguir, as demais equações utilizadas na composição do modelo (ORELLANA GONZÁLEZ, 2006).

Estimativa da demanda de água (em milhões de metros cúbicos)

$\mathrm{D}=$ DPOPULACIONAL + DAGP + DAMB 
em que,

$\mathrm{D}$ = quantidade total de água demandada;

DPOPULACIONAL = engloba por uma parte, a demanda urbana de água para consumo doméstico, e por outro, a demanda rural de água usada para os mesmos fins;

DAGP = demanda agrícola e pecuária de água;

$\mathrm{DAMB}=$ demanda ambiental de água.

\section{Demanda ambiental de água}

A demanda de água para a proteção do meio ambiente e dos ecossistemas será assumida como um valor constante. Para este estudo, se considerou igual a um volume mínimo registrado na estação pluviométrica sobre a bacia hidrográfica do rio Preto, denominada com o código 152 da rede existente no Estado de Minas Gerais que engloba uma série de cinqüenta 50 anos (TEIXEIRA SOUZA, 1993). De fato, tomou-se por base a vazão mínima registrada no estudo de Latuf (2007).

\section{Estimativa da oferta de água disponível}

$\mathrm{S}=\mathrm{SSUP}+\mathrm{SRET}$

em que,

$\mathrm{S}=$ oferta total de água disponível;

SSUP = oferta disponível de água superficial;

$\mathrm{SRET}=$ oferta disponível de águas de retorno.

\section{Índice de sustentabilidade}

É um dos critérios para avaliar se o funcionamento do sistema de recursos hídricos se encontra com vulnerabilidade e capacidade de recuperação (XU et al., 2002). Nesse estudo, o índice de sustentabilidade (IS) foi definido como a relação entre um possível déficit de água com respeito à oferta correspondente na mesma região, com os seguintes critérios:

$\mathrm{IS}=\{(\mathrm{S}-\mathrm{D}) / \mathrm{S}$ se $\mathrm{S}>\mathrm{D}$ e o se $\mathrm{S} \leq \mathrm{D}$

em que,

$\mathrm{D}=$ demanda de água;

$\mathrm{S}=$ oferta disponível de água.

Caso o valor de IS seja maior que 0,2 , indica um baixo ou nenhum estresse na oferta de água, o que implica que a demanda de água é menor ou igual a $80 \%$ da oferta potencial de água. Valores menores a 0,2 refletirão condições de vulnerabilidade, o que supõe que a demanda de água é maior que $80 \%$ da oferta potencial de água. Valores iguais a zero indicam que a oferta de água é insustentável, o que sugere que a demanda de água é igual ou excede a toda a disponibilidade de recursos hídricos locais.

\section{RESULTADOS E DISCUSSÃO}

Para se avaliar os possíveis efeitos das mudanças climáticas na região em estudo, o CENÁRIO "Mudanças Climáticas" considerou os efeitos de tais alterações, a partir dos acréscimos de $1^{\circ} \mathrm{C}$ na temperatura e de $6,9 \%$ na precipitação, sugeridos por Azevedo et al. (2005). Na Figura 4 observamse as relações existentes no CENÁRIO "Mudanças Climáticas", tendo como parâmetros os dados levantados pela estação fluviométrica Fazenda Barra da Égua (Latuf, 2007). Observa-se a criação de um novo reservatório (Reservatório da Bacia 3), onde será incorporado o aumento sugerido na precipitação.

Para se analisar os efeitos das mudanças climáticas têm-se de pensar em duas situações (NASCIMENTO, 2007): escassez e excesso de chuvas. Cabe lembrar que se faz necessário os conhecimentos de quais classes de usos do solo se agregaram às áreas de outras classes para a análise das contribuições de evapotranspiração/precipitação. Para a estação fluviométrica Fazenda Barra da Égua, Latuf (2007), constatou-se para o período 1985-2000, que o crescimento das áreas das classes de usos do solo "Mata" e "Cultivo" ocorreram, principalmente, em áreas de "Pasto" e "Cerrado", respectivamente. Merece destaque a redução das áreas de "Cerrado" $(-47,65 \%)$, que se deve ao avanço da fronteira agrícola, posto que a sua redução em $302,68 \mathrm{Km}^{2}$ no período $1985-2000,91,93 \%$ desse total se transformaram em áreas de "Cultivo". A substituição das áreas de "Pasto" (-78,99 $\left.\mathrm{Km}^{2}\right), 73,88 \%$ desse total se converteu em áreas de "Mata".

Para se verificar a influência das "Mudanças Climáticas", procedeu-se anteriormente a simulação do modelo considerando as condições atuais, CENÁRIO “Agronegócio atual”, sem os acréscimos de temperatura e precipitação propostos nesse cenário. Observou-se no ano de 2008, "Mata" contribuía com um volume de $1.500 \mathrm{~mm}$ ano ${ }^{-1}$ do volume precipitado na bacia; "Pasto", com $998 \mathrm{~mm}$ ano $^{-1}$; "Cerrado", com $900 \mathrm{~mm} \mathrm{ano}^{-1}$, enquanto que "Precipitação direta" na bacia era de $1.300 \mathrm{~mm} \mathrm{ha}^{-1}$. No CENÁRIO "Mudanças Climáticas", em função do acréscimo de $1^{\circ} \mathrm{C}$ na temperatura e de $6,9 \%$ na precipitação, no ano de 2008, "Mata" passou a contribuir com um volume de $1.550 \mathrm{~mm} \mathrm{ano}^{-1}$ do 
volume precipitado na bacia; "Pasto", com 1.098 $\mathrm{mm}$ ano $^{-1}$; "Cerrado", com $910 \mathrm{~mm}$ ano ${ }^{-1}$, enquanto que a "Precipitação direta" na bacia é de $1.320 \mathrm{~mm}$ ano $^{-1}$ (Figura 5).

Observa-se que apesar da precipitação na "Mata" ter aumentado em $50 \mathrm{~mm}$ ano ${ }^{-1}$, a precipitação direta na bacia aumentou em apenas $20 \mathrm{~mm}$ ano1; ou seja, a precipitação direta representa a média da evapotranspiração de cada uma das coberturas vegetacionais existentes nessa área, ceteribus paribus. Pode-se avaliar que, mesmo tendo havido acréscimo da classe de uso do solo "Mata" $(+11,86 \%)$ e acréscimo de $6,90 \%$ na precipitação, tais situações não foram suficientes para influenciar a média direta precipitada na bacia, posto ao significativo crescimento da classe de uso do solo "Cultivo" $(+198,09 \%)$ - essa classe não consegue manter a mesma taxa evapotranspirométrica que "Mata". Há de se considerar, ainda, que a classe "Cerrado", reduzida em 47,65\% $\left(-302,68 \mathrm{~km}^{2}\right)$, é o Bioma regional e representa a condição de homeostasia, foi substituída por "Cultivo" em 91,93\% de suas áreas.

A Figura 5 indica que a tendência de redução da precipitação direta na bacia persistirá até o final do período analisado desse estudo (2060). Observa-se que o volume precitado no ano de 1995 correspondia a $1.260 \mathrm{~mm} \mathrm{ano}^{-1}$; no ano de 2060 , será de $1.069 \mathrm{~mm} \mathrm{ano}^{-1}$; ou seja, uma tendência de redução em -15,16\% na precipitação.

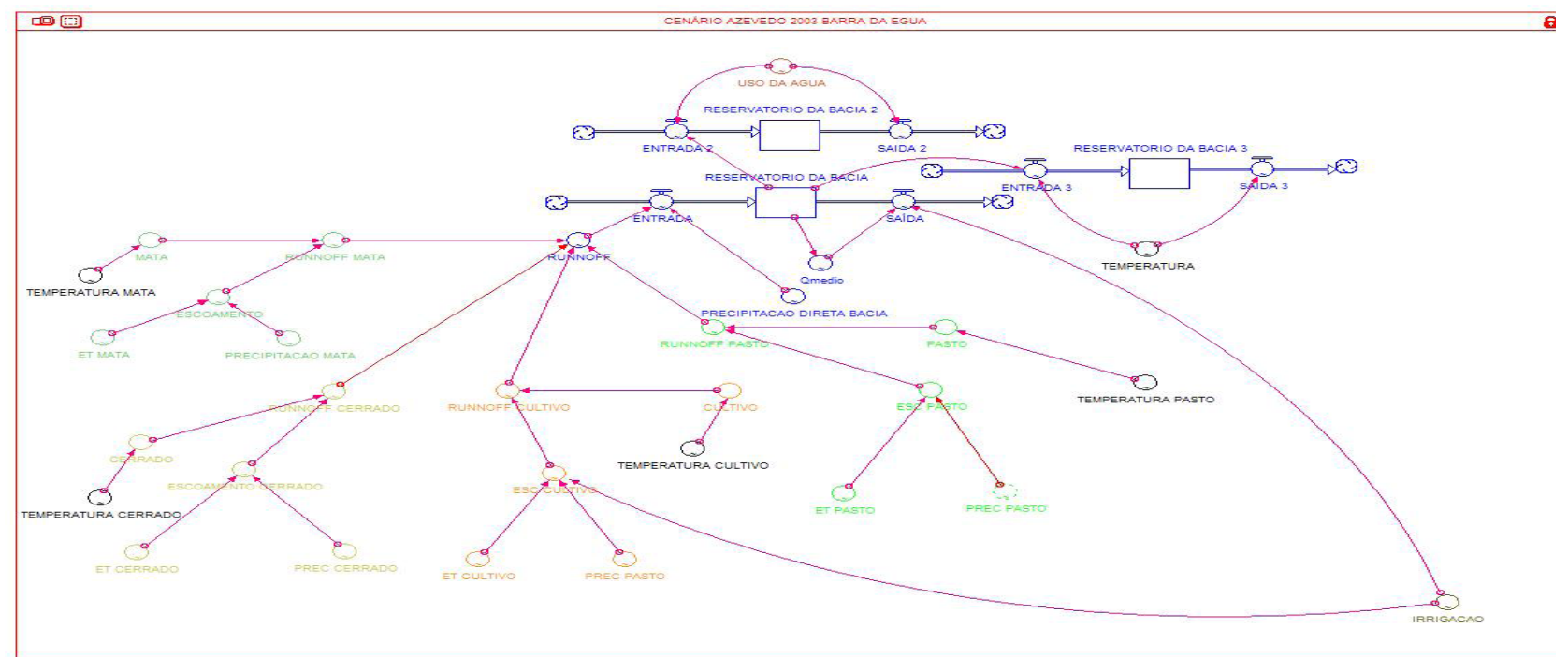

Figura 4. Modelo de estoque e fluxo da água do CENÁRIO "Mudanças Climáticas" na área de abrangência da estação fluviométrica Fazenda Barra da Égua.

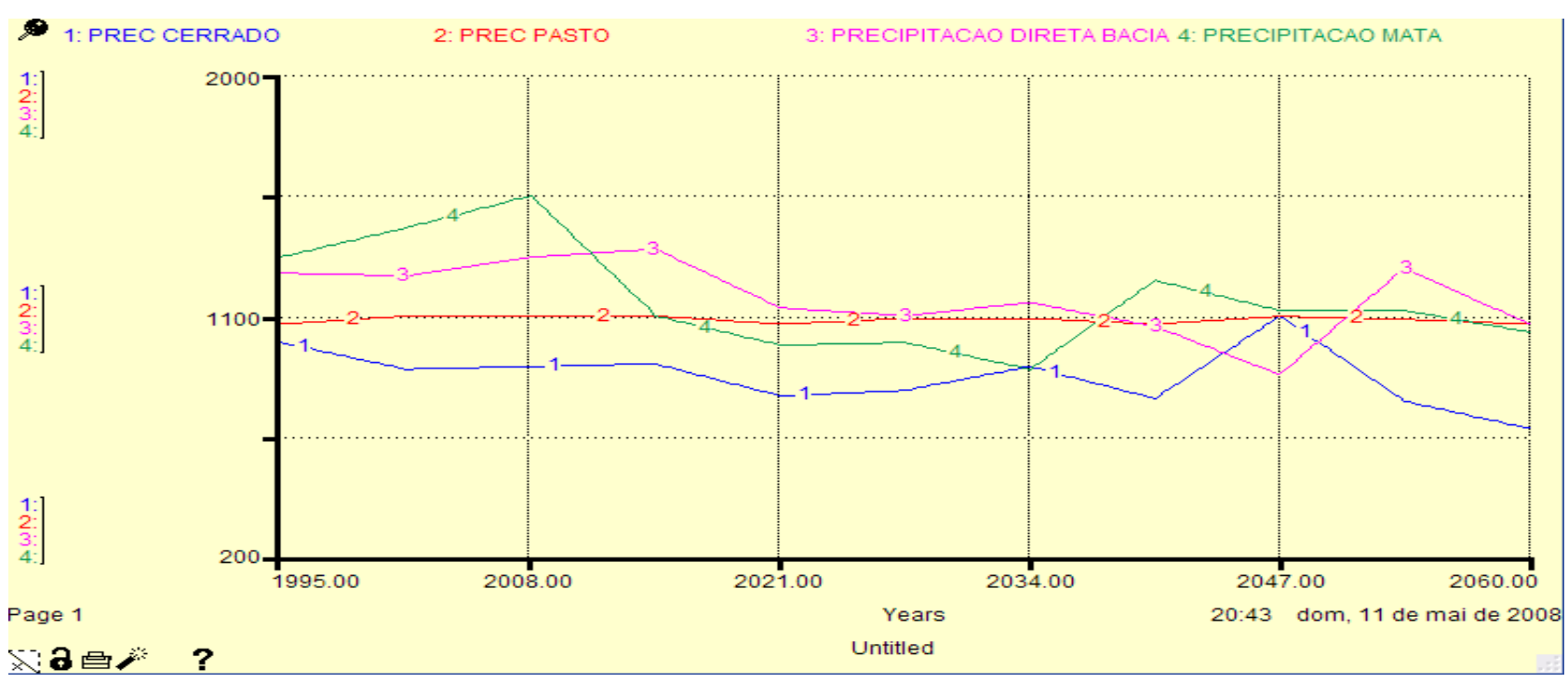

Figura 5. Precipitação e suas alterações $\left(\mathrm{mm} \mathrm{ano}^{-1}\right)$ em função das mudanças do uso do solo e climáticas para o período 1995-2060 na bacia do ribeirão Entre Ribeiros. 


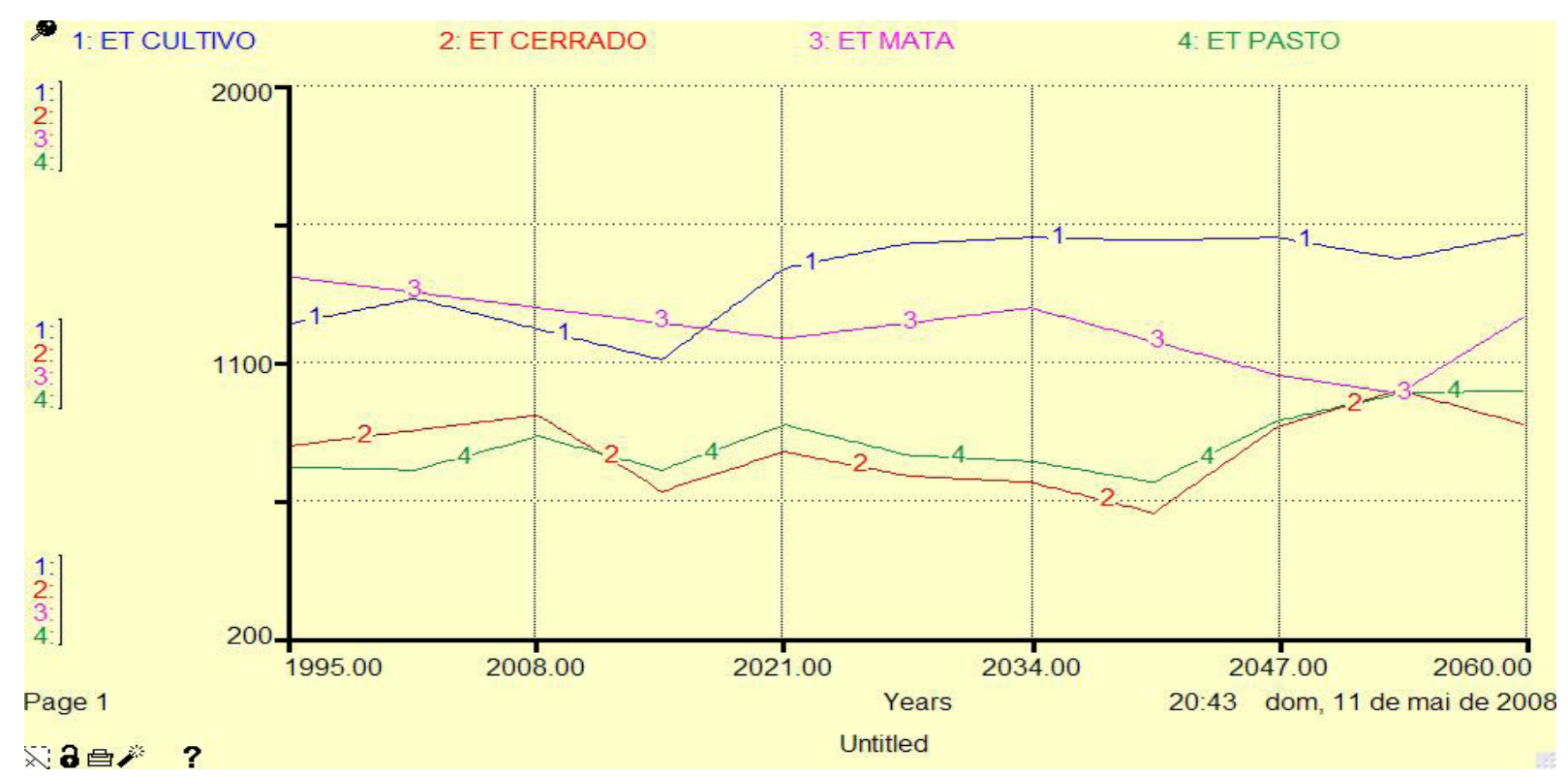

Figura 6. Evapotranspiração e suas variações em função das alterações do uso do solo e mudanças climáticas para o período 1995-2060.

Outro aspecto a ser observado se refere à temperatura média do ar. Apesar de sua elevação ter sido de apenas $1{ }^{\circ} \mathrm{C}$, a temperatura na "Mata" se elevou em $2,8^{\circ} \mathrm{C}$ ao final do período analisado (Quadro 1). Dessa forma, haverá maior perda de água por evapotranspiração, e consequentemente, maior seria a probabilidade de aumento das chuvas regionais, ceteribus paribus, desde que a classe de uso do solo "Cultivo" não tivesse sido a com tendência de maior expansão na região. Como comentado, essa classe de uso do solo não consegue manter as mesmas taxas evapotranspirométricas que "Mata".

Outra observação se refere à característica relativa à perda de água das espécies do "Cerrado" por evapotranspiração. A maioria das espécies desse Bioma possui mecanismos que auxiliam no controle estomático, reduzindo a sua perda de água por evapotranspiração em condição de temperaturas mais elevadas. Várias dessas espécies, em seu processo de fixação de carbono, o fazem por meio do metabolismo ácido das crassuláceas (CAM - Crassulacean Acid Metabolism). Este tipo de metabolismo ocorre em plantas típicas de regiões áridas, com altas temperaturas diurnas, baixas temperaturas noturnas e baixo teor de água no solo (SOUZA, 2008). Portanto, a substituição dessas espécies por outras exóticas, em cenário de mudanças climáticas, as taxas de evapotranspiração serão fortemente alteradas (Figura 6).

Verifica-se na Figura 6 que a maior contribuição para a Evapotranspiração era "Mata", no período 1995-2016. No CENÁRIO “Agronegócio atual”, era até o ano 2017; ou seja, a elevação de $1^{\circ} \mathrm{C}$ na temperatura média do ar e de $6,9 \%$ na precipitação, implicou em que o aumento da precipitação não tenha sido suficiente para que se mantivessem as mesmas taxas evapotranspirométricas. Com a sua substituição por "Cultivo", esse passa a ser o principal contribuinte para a evapotranspiração na área desta bacia, já no ano de 2016.

As áreas de "Cerrado" também apontam uma tendência de redução até o ano de 2040, quando volta a apontar crescimento até o ano de 2053, decrescendo novamente até o final do período analisado (2060) - comportamento semelhante ao apresentado no CENÁRIO "Agronegócio atual". Como já comentado, o Programa STELLA considera as inter-relações existentes entre os diversos parâmetros analisados de uma determinada área. Dessa forma, quando o modelo aponta para o aumento da contribuição da evapotranspiração do "Cerrado", significa que esta classe de uso do solo está sendo substituída por "Cultivo" irrigado, principalmente $(91,93 \%)$, e, ou "Mata", que apresentam maiores taxas de evapotranspiração. O mesmo comentário pode ser feito para "Pasto", que também está sofrendo as mesmas substituições, nesse caso, em 73,88\% das situações por "Mata". Avaliando os valores apresentados na Figura 6, observaram-se as seguintes variações das categorias de classe de uso do solo em estudo (Quadro 2). 
Quadro 1. Tendência de elevação da temperatura na classe de uso do solo "Mata" no período 1995-2060 na bacia do ribeirão Entre Ribeiros

\begin{tabular}{|c|c|c|c|}
\hline Ano & Temperatura Mata $\left({ }^{(} \mathbf{C}\right)$ & Ano & Temperatura Mata $\left({ }^{\mathbf{C}} \mathbf{C}\right)$ \\
\hline 1995 & 24,00 & 2027 & 26,00 \\
\hline 2001 & 24,00 & 2034 & 26,00 \\
\hline 2008 & 25,00 & 2040 & 26,70 \\
\hline 2014 & 25,00 & 2047 & 26,80 \\
\hline 2021 & 25,00 & 2060 & 26,80 \\
\hline
\end{tabular}

Quadro 2. Variação na taxa de Evapotranspiração no período 1995-2060 para categorias selecionadas

\begin{tabular}{|c|c|c|c|c|}
\hline $\begin{array}{c}\text { CENARIO } \\
\text { (\%) }\end{array}$ & Pasto & Cultivo & Cerrado & Mata \\
\hline "Agronegócio Atual" & $+35,62$ & $+24,17$ & 0,0 & $-11,11$ \\
\hline "Mudanças Climáticas" & $+33,34$ & $+23,77$ & $+8,54$ & $-9,49$ \\
\hline
\end{tabular}

1: USO DA AGUA

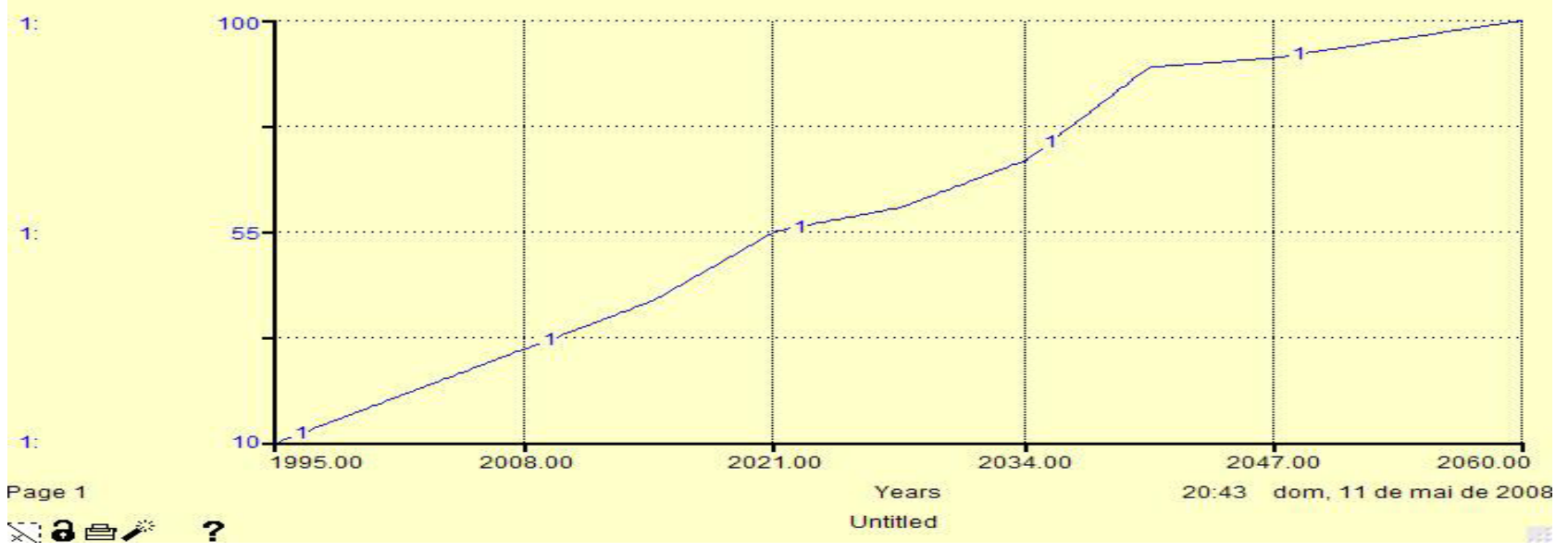

Figura 7. Simulação para o uso da água no período 1995-2060 na bacia do ribeirão Entre Ribeiros.

Analisando o Quadro 2 verifica-se uma variação significativa na contribuição das taxas evapotranspirométricas para as áreas de "Pasto" e "Cultivo". Por outro lado, o crescimento das áreas de "Cultivo" (+306,41 km²) implicou em redução percentual da contribuição das áreas de "Mata" $(+73,58$ $\mathrm{km}^{2}$ ). Relacionando o Quadro 2 à Figura 6, sugere que sendo as áreas de "Cultivo" as principais responsáveis pela evapotranspiração nesse novo cenário, a tendência aponta para a redução da precipitação regional, ceteribus paribus. Esse mesmo comportamento foi observado no trabalho de Latuf(2007), onde as variáveis hidrológicas vazões máxima, mínima e média, assim como a precipitação anual e a do mês mais chuvoso tiveram tendências gerais de redução ao longo do período analisado (1985-2000), contrastando ao crescimento do uso da água na bacia (Figura 7).

A Figura 7 apresenta a tendência de uso total de água na bacia, tendo por base os dados da estação fluviométrica Fazenda Barra da Égua. No CENÁRIO "Agronegócio atual" em 1995 eram consumidos 10\% do total de toda a água disponível da bacia; em 2005, a simulação aponta para um consumo de $25,38 \%$; em 2010, 33,08\%; em 2015, 41,15\%; em 2025, 58,46\%; em 2034, 70\%; em 2039, 81,54\%; e em 2047, para uma demanda de $90 \%$ de toda a água disponível da bacia. Quando se analisa o consumo de água no CENÁRIO "Mudanças Climáticas", observa-se que até o ano de 2034 a demanda pelo recurso água é idêntico, mas a partir desse ano, o consumo começa a aumentar: em 2039 a demanda por água já representa $85 \%$ e, em $2047,92 \%$ de toda a água disponível da bacia.

Observa-se que quando se comparam os consumos do ano de 2034, a diferença entre os referidos CENÁRIOS chega ser de 3,46\%, e em 2047 essa diferença cai para $2 \%$. Tal fato pode ser explicado pela evapotranspiração no CENÁRIO "Agronegócio atual”, em 2034, para "Cultivo", era de $1.470 \mathrm{~mm}^{-1} \mathrm{ano}^{-1}$. 
Quadro 3. Comportamento da "Precipitação direta" na bacia no período 1995-2060

\begin{tabular}{|c|c|c|c|}
\hline $\begin{array}{ll}\text { CENÁRIO } & \text { Ano } \\
\end{array}$ & $\begin{array}{c}1995 \\
\left(\mathrm{~mm} \mathrm{ano}^{-1}\right)\end{array}$ & $\begin{array}{c}2060 \\
\left(\mathrm{~mm} \mathrm{ano}^{-1}\right)\end{array}$ & $\begin{array}{c}\text { Variação } \\
(\%)\end{array}$ \\
\hline "Agronegócio atual" & 1.230 & 1.000 & $-18,70$ \\
\hline "Mudanças Climáticas" & 1.260 & 1.069 & $-15,16$ \\
\hline
\end{tabular}

No CENÁRIO "Mudanças Climáticas", nesse mesmo ano de 2034, a evapotranspiração era de 1.500 $\mathrm{mm}$ ano $^{-1}$. Ou seja, apesar de ter havido elevação da precipitação em $6,9 \%$, sugerindo o aumento da oferta de água, houve estímulo ao incremento de "Cultivo". Contudo, em função da elevação da temperatura, a taxa evapotranspirométrica aumentou, considerandose que "Cultivo" não consegue reter e armazenar água no solo tal como "Mata", a oferta real de água na bacia não se elevou.

Na verdade, a "Precipitação direta" na bacia sofreu uma redução de 15,16\% (1.260 mm ano ${ }^{-1}$ para 1.069 $\mathrm{mm}$ ano $^{-1}$ ) no período analisado (1995-2060). Dessa forma, a partir do momento em que se percebeu tal tendência, novamente o uso da água foi reduzido. Quando se compara com o CENÁRIO “Agronegócio atual", observa-se que o volume precitado no ano de 1995 correspondia a $1.230 \mathrm{~mm}^{2} \mathrm{ano}^{-1} \mathrm{e}$ no ano de 2060 , $1.000 \mathrm{~mm} \mathrm{ano}^{-1}$; ou seja, uma redução de $-18,70 \%$ na precipitação. No Quadro 3 verifica-se no CENÁRIO "Mudanças Climáticas", que em função da elevação da temperatura em $1^{\circ} \mathrm{C}$ e com o aumento de $6,9 \%$ na precipitação, a redução no volume precipitado direto na bacia foi inferior que no CENÁRIO “Agronegócio atual".

$\mathrm{Na}$ análise do Quadro 3, justifica-se tal comportamento em função do aumento da temperatura que provocou a elevação das taxas evapotranspirométricas, aumentando o volume precipitado no CENÁRIO "Mudanças Climáticas". Contudo, ao longo do período analisado (19952060), observou-se que a precipitação direta na bacia foi reduzida. Tal fato se deu, provavelmente, em função da mudança do uso do solo, de "Cerrado" para "Cultivo", que não consegue manter a mesma taxa evapotranspirométrica em face das operações realizadas no preparo do solo, que causam a sua compactação e aumentam as perdas de água por escoamento superficial, implicando em menor capacidade de armazenamento de água no solo e a perda da condição de homeostasia, influenciando na redução das vazões média e mínimas.

Da mesma forma que no CENÁRIO "Agronegócio atual", considerando que a condição de vulnerabilidade ocorre quando a demanda de água é superior a $80 \%$ da oferta potencial de água, o ano de 2032 apontou para uma condição de estresse. No CENÁRIO "Mudanças Climáticas", o ano de 2039 aponta para a condição de que o sistema já apresentaria um forte estresse hídrico (IS $=0,20)$. Há de se considerar que a bacia hidrográfica do rio São Francisco é totalmente dependente do nível e da distribuição das chuvas. Dessa forma, aí está a importância de se prever o comportamento hidrológico a partir de mudanças climáticas, que poderá elevar a necessidade de escolha entre usos, por exemplo, irrigação ou geração de energia, proteção da vida aquática ou diluição de esgoto.

\section{CONCLUSÕES}

- O modelo matemático de estoque e fluxo da água desenvolvido neste trabalho com o uso do programa STELLA permitiu simular modificações de uso do solo na bacia hidrográfica do ribeirão Entre Ribeiros;

- A simulação apontou para uma tendência de redução de $-15,16 \%$ na precipitação direta na bacia em cenário de "mudanças climáticas" e de -18,70\% no cenário "Agronegócio Atual”;

- Foram observadas alterações significativas nas taxas evapotranspirométricas para "Pasto" $(+33,34 \%)$; "Cultivo" (+23,77\%); "Cerrado" (+8,54\%); e "Mata" (-9,49\%);

- A tendência apontada pelo modelo, quando calculado o "Índice de Sustentabilidade", sugere que o sistema em estudo tende a exaustão ou depleção de seus recursos hídricos;

- Relacionado ao uso do solo, percebe-se que a substituição de "Cerrado" por "Cultivo" tem sido a principal responsável pela redução das vazões média e mínimas;

- O modelo desenvolvido neste trabalho é um valioso instrumento computacional de auxílio aos formuladores de políticas públicas, principalmente em cenário de mudanças climáticas, para o planejamento, gestão e monitoramento dos recursos hídricos: para a bacia do ribeirão Entre Ribeiros, como também para outras bacias hidrográficas. 
REFERÊNCIAS BIBLIOGRÁFICAS

AB' SABER, A.N. Sertões e sertanejos: Uma geografia humana sofrida. Estudos avançados: Dossiê Nordeste seco v.13, n.36, p.7-59, 1999.

ANA - Agência Nacional de Águas. A evolução da gestão dos recursos hídricos no Brasil. Brasília: ANA, 76 p. 2003. (Edição comemorativa do Dia Mundial da Água)

AZEVEDO, S.V.; MACIEL, L.F.F.; PEREIRA, M. E. A Bacia do Rio Paracatu, Minas Gerais. Campinas: Universidade Estadual de Campinas. 2005. 9p. Disponível em: www.futurasgeracoes. com.br. Acesso em: 23 nov. 2007.

CBHSF - Comitê da Bacia Hidrográfica do Rio São Francisco. Plano de recursos hídricos da bacia hidrográfica do rio São Francisco. Salvador, BA: CBHSF, 2004. 337p.

FERREIRA, P.A.; EUCLYDES, H.P. Recursos hídricos e tecnologia necessária aos projetos hidroagrícolas: bacia do Paracatu. Viçosa, MG: UFV/DEA, 200p. 1997.

GISS - Goddard Institute for Space Studies. Climate change from short-lived emissions. Disponível em: http://www.giss.nasa.gov. Acesso em: 23 out. 2008.

GLEICK, P.H.; KIPARSKY, M. The Water \& Climate Bibliography. In: GLEICK, P. H. (ed.) The World's Water: The Biennial Report on Freshwater Resources. Washington, DC: Island Press, p.22833, 2004.

LATUF, M.O. Impacto das mudanças do uso do solo nas vazões observadas nas bacias do rio Preto e ribeirão Entre Ribeiros, MG. Viçosa, MG: UFV, 2007. 103p. Dissertação (Mestrado em Engenharia Agrícola) - Universidade Federal de Viçosa, 2007.

Ministério do Meio Ambiente - MMA \& Secretaria de Recursos Hídricos - SRH-MMA. Plano nacional de recursos hídricos: Caderno da região hidrográfica do São Francisco. Brasília, DF: MMA, 2006. 148 p.
NASCIMENTO, L. Teleconexões, mudanças climáticas e a bacia hidrográfica do rio São Francisco. Leituras cotidianas, v.57, n.298, p.3445, 2007. Disponível em: www.pfilosofia.xpg.com. br/07_leituras_cotidianas/20070212a. Acesso em: 12 jul. 2008.

ODUM, E. P. Ecologia. Rio de Janeiro: Guanabara, 1988. 434p.

ORELLANAGONZÁLEZ,A. M. G. Sustentabilida de los recursos hídricos en São Miguel do Anta, Minas Gerais: un enfoque de dinámica de sistemas. Viçosa, MG: UFV, 2006. 104p. Dissertação (Mestrado em Economia Aplicada) - Universidade Federal de Viçosa, 2006.

OYAMA, M.D.; NOBRE, C.A. Climatic Consequences of a Large-Scale Desertification in Northeast Brazil: A Gcm Simulation Study. Journal of Climate, v.17, n.16, p.3203-13, 2004.

PRUSKI, F.F.; PEREIRA, S.B.; NOVAES, L.F.; SILVA, D.D.; RAMOS, M.M. Comportamento hidrológico na foz do rio São Francisco durante período de 1950 a 1999. Viçosa: Engenharia na Agricultura, v.13, n.2, p.118-123, 2005.

RESENDE, M; KER, J.C.; BAHIA FILHO, A.F. C. Desenvolvimento sustentado do cerrado. In: ALVAREZ V., H.V.; FONTES, L.E.F.; FONTES, M. P. F. O solo nos grandes domínios morfológicos do Brasil e o desenvolvimento sustentável. Viçosa, MG: SBCS; UFV, DPS, 1996. p.169-199.

RODRIGUEZ, R.D.G. Metodologia para a estimativa das demandas e disponibilidades hídricas: estudo de caso da bacia do Paracatu. Viçosa, MG: UFV/DEA, 2004, 111 p. Dissertação (Mestrado em Engenharia Agrícola) - Universidade Federal de Viçosa, 2004.

RODRIGUEZ, R.D.G.; PRUSKI, F.F.; NOVAES, L.F.; RAMOS, M.M.; SILVA, D.D.; TEIXEIRA, A.F. Estimativa da demanda de água nas áreas irrigadas da bacia do rio Paracatu. Engenharia agrícola, Jaboticabal, vol.27, n.1, p.34-42, 2007.

SALATI, E. Emissão e seqüestro de CO2 - uma nova oportunidade de negócios para o Brasil. In: I SEMINÁRIO SOBRE EMISSÃO E SEQÜESTRO 
DE CARBONO - COMPANHIA VALE DO RIO DOCE, 1994, Rio de Janeiro. Anais... Rio de Janeiro: CVRD, 1994. p.12-37.

SANTOS, N.A.P.; CAMARGOS, L.M.M.; SERPA, C.F.O uso de técnicas de geoprocessamento como subsídio para a elaboração de propostas de enquadramento dos corpos de água: o caso da bacia hidrográfica do Rio Paracatu. XIII Simpósio Brasileiro de Sensoriamento Remoto. Anais... Florianópolis, Brasil: INPE, 2007, p.3533-3540.

SOUZA, M.N. Agrometeorologia e as mudanças climáticas: conceitos, terminologias e aplicações. Apostila da Disciplina Agrometeorologia do Curso Superior de Agroecologia. Rio Pomba: CEFET, 2008. 258p. (Caderno Didático número 54).

SOUZA, M.N. Degradação e recuperação ambiental e desenvolvimento sustentável. Viçosa, MG: UFV, 2004. 371p. Dissertação (Mestrado em Ciência Florestal) - Universidade Federal de Viçosa, 2004.

SOUZA, S.M.T. (Coord.). Deflúvios superficiais no estado de Minas Gerais. Belo Horizonte: Hidrossistemas, 1993. 325p.

TUCCI, C.E.M.; HESPANHOL, I.; CORDEIRO NETTO, O. M. Gestão de água no Brasil. Brasília: UNESCO, 2001. 156p.

XU, Z.X.; JINNO, K.; KAWAMURA, A.; TAKESAKI, S.; ITO, K. Sustainability analysis for yellow river water resources using the system dynamics approach. Water Resources Management, Netherlands, n.16, p.239-261, 2002. 